\title{
Esmaltes Transparente e Mate para Grês Porcelanato Polido
}

\author{
Helder J.C. Oliveiraa ${ }^{a}$ João António Labrinchab* \\ ${ }^{a}$ Estúdio Cerâmico Lda-IFH, Aveiro, Portugal \\ ${ }^{b}$ Departamento de Engenharia de Materiais e Cerâmica, Universidade de Aveiro - CICECO, Aveiro, Portugal \\ *e-mail: jal@ua.pt
}

\begin{abstract}
Resumo
O presente trabalho detalha o estudo de novas composições de esmaltes (brilhante e mate transparentes), preparados por via úmida, para grés porcelânico polido. Esta técnica permite a redução de custos, devido à diminuição da quantidade de material a aplicar, sem comprometer as características técnicas exigidas a estes produtos e garantindo elevada variabilidade estética (cor, textura, brilho, etc) através da decoração digital InkJet, nomeadamente nos tons intensos (negro e castanho). A obtenção de uma camada menos espessa e mais homogênea, requerendo polimento menos profundo, ajusta-se à tendência da indústria de pavimento e revestimento para produzir peças polidas, cada vez mais em grandes formatos. Este novo método de aplicação de esmaltes permite obter superfícies polidas que cumprem os requisitos técnicos exigidos nas normas actualmente em vigor e, ao mesmo tempo, reduz os custos com o material a aplicar e nas etapas de acabamento, particularmente no polimento. Procedeu-se à caracterização dos esmaltes transparente e mate aplicados. As peças foram queimadas à temperatura de $1220^{\circ} \mathrm{C}$, com um ciclo de queima cuja duração, de acordo com o formato, pode oscilar entre $60 / 70$ minutos. Foi avaliada a resistência da camada ao ataque à mancha, ao ataque químico, à abrasão e mediu-se a dureza (MOHS).
\end{abstract}

Palavras chave: porcelânico polido, lapato, cromático, matizante, fusibilidade, maturação.

\section{Introdução}

A necessidade de desenvolver produtos cerâmicos diferenciados e esteticamente apelativos realçou, nos últimos anos, a importância das etapas de acabamento superficial das peças de pavimento e revestimento no sentido de garantir a obtenção de novos efeitos decorativos. Esta tendência gerou o desenvolvimento de atomizados e/ou granilhas e mais recentemente, a investigação de novas fritas e formulações de esmaltes [1] com superiores propriedades técnicas e variabilidade estética (cor, textura, etc.). As peças com este tipo de acabamento apresentam atualmente elevada resistência à abrasão e ao risco, sem porosidade superficial depois do polimento.

A aplicação destes esmaltes é feita após aplicação de engobe, sendo depois efetuada a decoração digital, por Inkjet, em pistolas "air less" tipo Jet. Em geral usam-se valores de densidade de 1500/1600g/L, com aplicações de $60 / 70 \mathrm{~g}$ no formato $30 \times 30$ [2], obtendo-se uma superfície bem estirada pelo uso de fluidificantes líquidos com propriedades autonivelantes. A figura 1 mostra uma unidade de aplicação destes esmaltes por Jet [3].

A aplicação com pistolas "air less", fixas ou móveis dependendo do tamanho do formato, requer menor quantidade de esmalte, o que diminui o custo do produto. Permite bom espalhamento do esmalte e secagem mais uniforme, o que assegura boa textura de acabamento. Em consequência, as etapas de polimento subsequentes podem ser feitas a menor profundidade, ou apenas superficialmente, do tipo "lapato" total. Antes do polimento, os produtos possuem aspecto brilhante ou mate transparente, tal como se exemplifica na figura 2. O controle é feito sobre barras de diferentes cores, aplicada de forma digital, sendo bem vísivel o bom desenvolvimento cromático e respetivas intensidades [2].

Estas novas composições de esmaltes aumentam a variabilidade estética das peças produzidas em porcelânico polido, nomeadamente na obtenção de produtos marmorizados por decoração digital, em tons intensos de negro e castanho, como se ilustra na figura 3. Além disso alargam o campo de aplicação para formatos maiores (90x90 / 60x120 / 150x300), a utilizar em zonas de maior tráfego, devido à possibilidade de aplicar decoração digital por inkjet, em sandwiche, entre o engobe e esmalte.

\section{Procedimento Tecnológico e Experimental}

Caracterizaram-se os esmaltes a usar e determinou-se a composição química por fluorescência de raios X (FRX), avaliou-se o comportamento térmico ATD (dilatometria e microscopia de aquecimento por teste de fusibilidade), analisou-se a microestrutura por microscopia eletrônica de varredura (MEV) e avaliaram-se eventuais fases cristalinas por difração de raios $\mathrm{X}$ (DRX).

O esmalte mate é constituído por $40 \%$ (em massa) de frita (mate), sendo a fração restante uma mistura de componentes crus (feldspato, wollastonite, alumina e caulino). O esmalte transparente é constituído por teor expressivamente superior (80\%) de frita (transparente e de elevado brilho), tendo nefelina, caulim e argila micronizada como matérias-primas cruas. Ambos os esmaltes foram moídos com $40 \%$ de água, utilizando 
$0.3 \%$ de um ligante (CMC) de viscosidade média, $0.1 \%$ de defloculante (tripolisfosfato de sódio) e $0.05 \%$ de conservante anti bactericida. Os resíduos de moagem em peneira de $45 \mu \mathrm{m}$ são de 1-2 g no caso do esmalte mate e $10-12 \mathrm{~g}$ para o esmalte transparente. Esta diferença justifica-se pelo elevado teor de frita presente no esmalte transparente. Ambos os esmaltes foram peneirados numa tela de abertura igual a \#120 mesh, seguindo-se um tempo de repouso de $24 \mathrm{~h}$, sob agitação lenta, antes da sua utilização na esmaltação, garantindo-se assim, a eliminação do ar existente nas suspensões, introduzido durante a moagem.

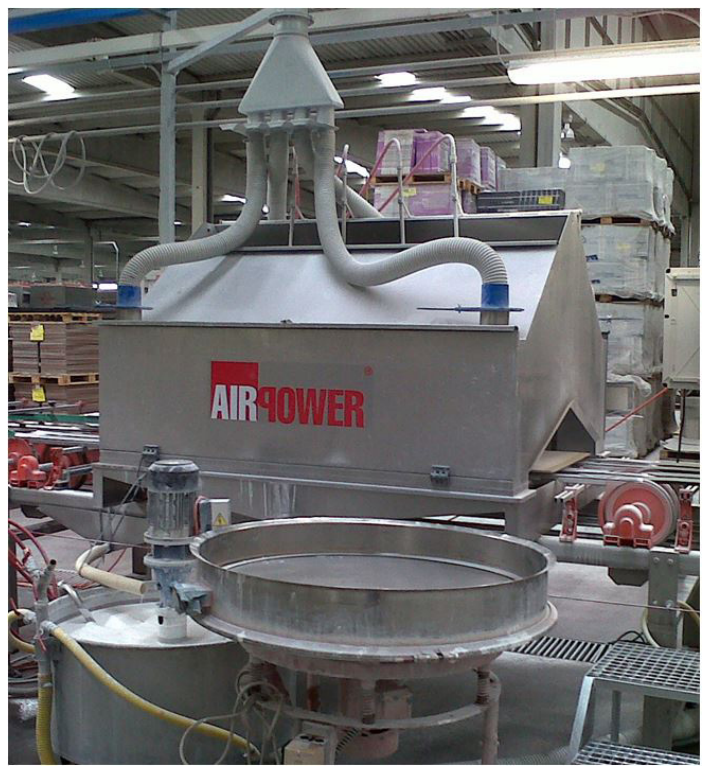

Figura 1. Aplicação de esmalte por cabine a Jet.

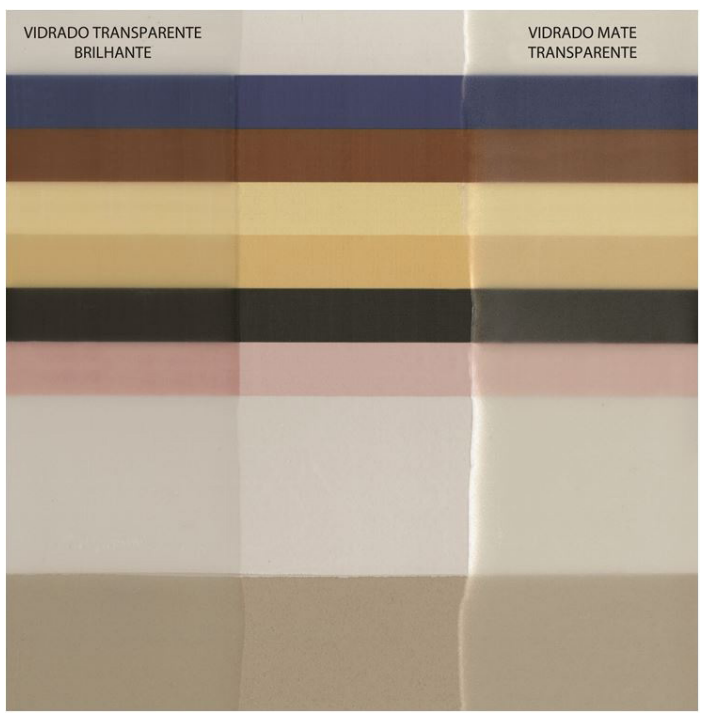

Figura 2. Esmaltes transparente brilhante e mate transparente antes de polir.
Os esmaltes foram aplicados por Jet, a partir de uma suspensão com densidade entre 1520/1540 g/L, viscosidade de 15" (Copo Ford com 4mm de diâmetro) e massa de $70 \mathrm{~g}$ no caso de peças $30 \times 30 \mathrm{~cm},[2]$. As peças obtidas foram queimadas à temperatura máxima de $1220^{\circ} \mathrm{C}$, num ciclo com duração total de duração total de 60-70 minutos, seguindo-se operações de polimento e aplicação de cera líquida com função "tapa poros".

Posteriormente as peças foram analisadas visualmente e avaliou-se a resistência da camada de esmalte ao ataque às manchas, iodo, azeite, contato com pasta vermelha de Fe e pasta verde de Cr, e ainda marcador azul E 3000, de acordo com a norma ISO 10545-14 [6]. A resistência ao ataque químico foi verificada limpando a superfície da peça de teste com um solvente (acetona) e secando completamente antes de iniciar o teste. As substâncias de teste utilizadas foram ácido clorídrico (3\% e 18\% de concentração), ácido cítrico, ácido láctico e hidróxido de potássio $(30 \mathrm{~g} / \mathrm{L}$ e $100 \mathrm{~g} / \mathrm{L})$. Colocaram-se pedaços de peças em contacto com as substâncias de teste durante $24 \mathrm{~h}$ (ácido cítrico e láctico) e 96h (ácido clorídrico e hidróxido de potássio), segundo a norma ISO 10545-13 [6].

A resistência à abrasão (PEI - Porcelain Enamel Institute) foi medida de acordo com a norma ISO 10545-7 e a dureza foi medida de acordo com a resistência ao risco usando-se a escala de MOHS [7].

\section{Resultados}

\subsection{Caracterização dos materiais}

A tabela 1 mostra as composições químicas do esmalte transparente e mate, expressa em \% ponderal dos óxidos, obtida por fluorescência de raios X (FRX). Cabe salientar a ausência de zircônio como opacificante, em ambas as composições, estando de acordo com o caráter

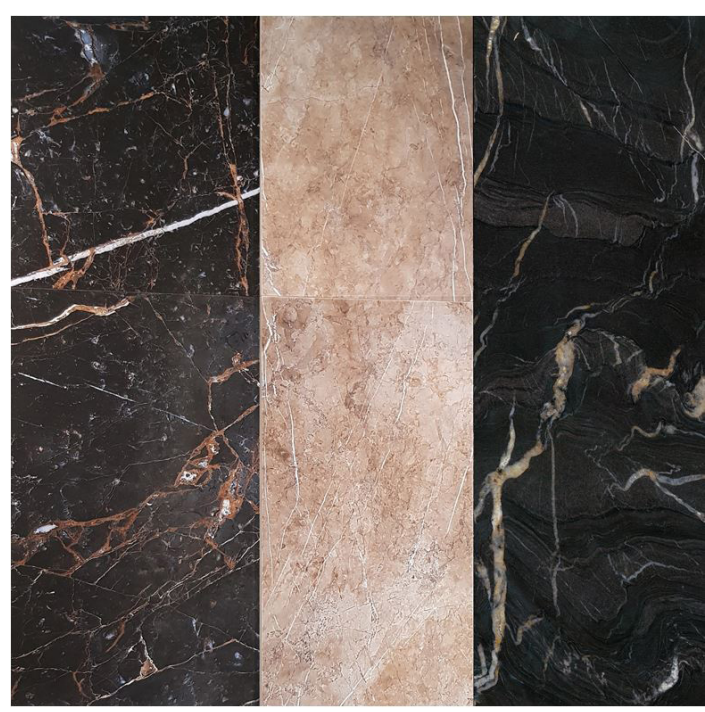

Figura 3. Marmorizados polidos, negro e castanho, obtidos por decoração digital em sandwiche. 
transparente de ambos os esmaltes. No esmalte mate, o superior valor de perda ao fogo resulta do maior teor em matérias-primas cruas. Cabe destacar também os teores elevados de alumina e cálcio, componentes essenciais para este tipo de composições de alta temperatura, ao mesmo tempo que é relativamente reduzida a concentração de elementos alcalinos, sódio e potássio. Com isto diminui-se a ocorrência de defeitos superficiais, particularmente na fase de desgaseificação $\left(\mathrm{T}=750-950^{\circ} \mathrm{C}\right)$, uma vez que

Tabela 1. Composição química do esmalte transparente (VTG 066) e do esmalte mate (VMG 205), obtida por fluorescência de raios $\mathrm{X}$ (FRX).

\begin{tabular}{ccc}
\hline $\begin{array}{c}\text { (\%) ponderal } \\
\text { Óxidos }\end{array}$ & $\begin{array}{c}\text { Esmalte } \\
\text { transparente } \\
\text { VTG 066 }\end{array}$ & $\begin{array}{c}\text { Esmalte mate } \\
\text { VMG 205 }\end{array}$ \\
\hline $\mathrm{SiO}_{2}$ & 54,0 & 43,8 \\
$\mathrm{Al}_{2} \mathrm{O}_{3}$ & 11,4 & 18,2 \\
$\mathrm{CaO}$ & 14,6 & 18,0 \\
$\mathrm{MgO}$ & 1,4 & 1,8 \\
$\mathrm{Na}_{2} \mathrm{O}$ & 2,2 & 2,3 \\
$\mathrm{~K}_{2} \mathrm{O}$ & 4,5 & 2,2 \\
$\mathrm{BaO}_{\mathrm{ZnO}}$ & 3,3 & \\
\hline $\mathrm{TiO}_{2}$ & 6,0 & 4,2 \\
$\mathrm{Fe}_{2} \mathrm{O}_{3}$ & 0,06 & 0,07 \\
\hline perda ao fogo & 0,1 & 0,2 \\
\hline & 0,7 & 8,6 \\
\hline
\end{tabular}

Tabela 2. Valores das temperaturas que traduzem a fusibilidade de cada esmalte.

\begin{tabular}{lcc}
\hline \multicolumn{1}{c}{ Temperaturas } & $\begin{array}{c}\text { Esmalte } \\
\text { transparente } \\
\text { VTG 066 }\end{array}$ & $\begin{array}{c}\text { Esmalte } \\
\text { mate } \\
\text { VMG 205 }\end{array}$ \\
\hline A-Sinterização $\left({ }^{\circ} \mathrm{C}\right)$ & 1042 & 1090 \\
B-Amolecimento $\left({ }^{\circ} \mathrm{C}\right)$ & 1115 & 1155 \\
C-Esfera $\left({ }^{\circ} \mathrm{C}\right)$ & 1132 & 1160 \\
D-Semi esfera $\left({ }^{\circ} \mathrm{C}\right)$ & 1158 & 1171 \\
E-Fusão $\left({ }^{\circ} \mathrm{C}\right)$ & 1185 & 1180 \\
\hline
\end{tabular}

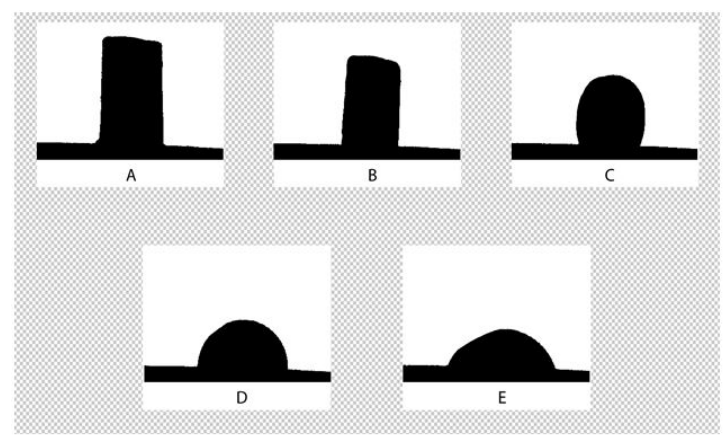

(I) o material é menos fundente. A presença de zinco em ambos os esmaltes justifica-se pelo seu carater matizante (no esmalte mate acetinado) e simultaneamente fundente de alta temperatura (no esmalte transparente), garantindo assim, elevado brilho e o adequado espalhamento da superfície.

Os coeficientes de expansão térmica, avaliados entre $50-400^{\circ} \mathrm{C}$, são iguais a $63.2 \times 10^{-7}$ e $66.8 \times 10^{-7}{ }^{\circ} \mathrm{C}^{-1}$ (erro de $+/-2$ ), para o esmalte transparente e mate, respectivamente. É de se esperar um bom acordo com o suporte, que possui $\alpha=71 \times 10^{-7} \mathrm{C}^{-1}$. Como complemento aos dados dilatométricos a tabela 2 mostra os diferentes valores das temperaturas que traduzem a fusibilidade dos esmaltes, obtidos por microscopia de aquecimento. A figura 4 mostra a evolução da fusibilidade dos esmaltes, que permitiu estimar os valores daquelas temperaturas [3].

Cabe destacar as temperaturas elevadas de amolecimento (B) dos dois esmaltes, sendo superior em $40^{\circ} \mathrm{C}$ a do esmalte mate devido ao superior teor de componentes crus, naturalmente menos fusíveis (em especial a wollastonite e alumina). Apesar das diferenças de composição, as temperaturas de fusão (E) são muito próximas e ambas elevadas. Estes valores são especialmente adequados para uso em grés porcelânico, que é queimado entre 1180 e $1220^{\circ} \mathrm{C}$, uma vez que os esmaltes mantêm uma desejável permeabilidade, permitindo o escape de gases gerados no suporte cerâmico. Minimizam-se desta forma os riscos de formação de defeitos como furinhos e/ou bolhas, comuns em suportes cerâmicos de baixa porosidade e absorção de água inferior a $0.5 \%$. Os esmaltes apresentam textura bem desenvolvida e elevado grau de maturação, reduzindo-se o risco de surgimento de poros superficiais na fase de polimento, que acarretam o rápido acumulo de sujeira sobretudo em ambientes de alto tráfego.

Foi feita a observação em microscópio eletrônico de varredura (MEV), de ambos os esmaltes (figura 5). É de realçar o carácter fortemente homogéneo e vítreo de ambos os esmaltes.

As figuras 6 e 7 mostram espectros de EDS das amostras visualizadas no $\mathrm{MEV}$, com indicação dos elementos químicos presentes e da respectiva concentração (ver tabelas 3 e 4). O maior destaque vai para os teores superiores de cálcio

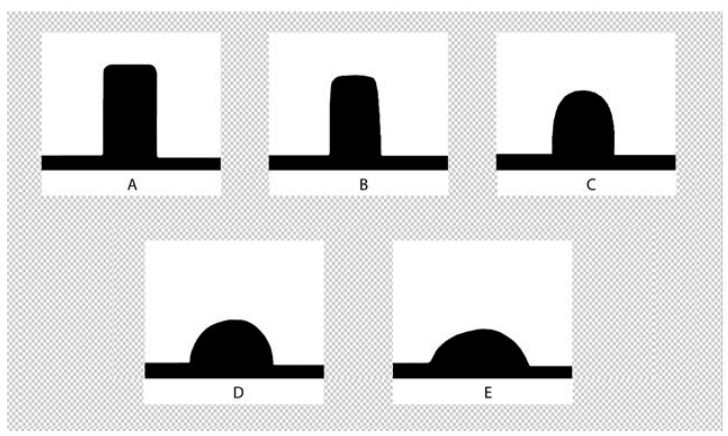

(II)

Figura 4. Imagens das temperaturas características da fusibilidade do esmalte transparente VTG 066 (I) e do esmalte mate VMG 205 (II). 


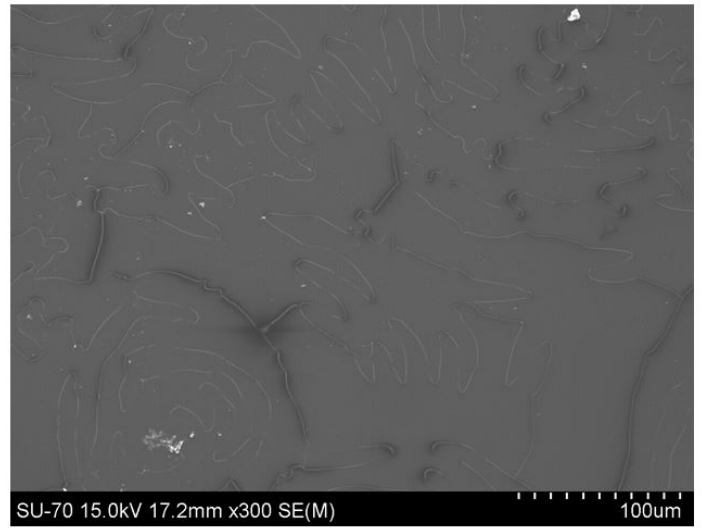

(I)

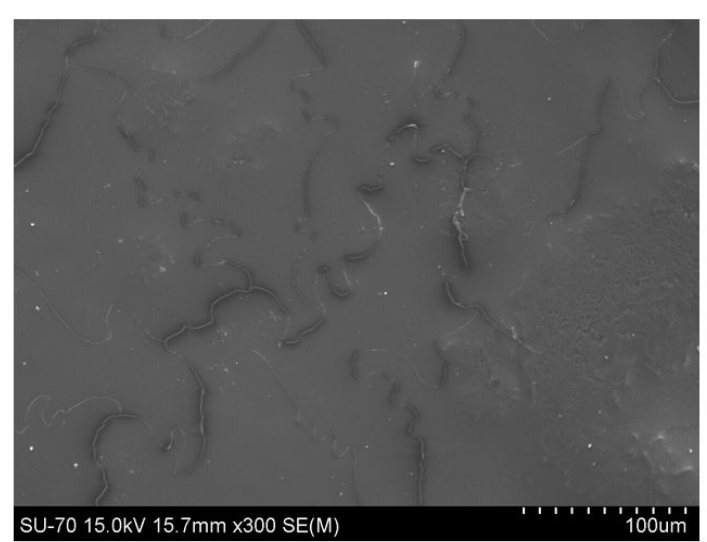

(II)

Figura 5. Micrografias do esmalte transparente VTG 066 (I) e do esmalte mate VMG 205 (II).

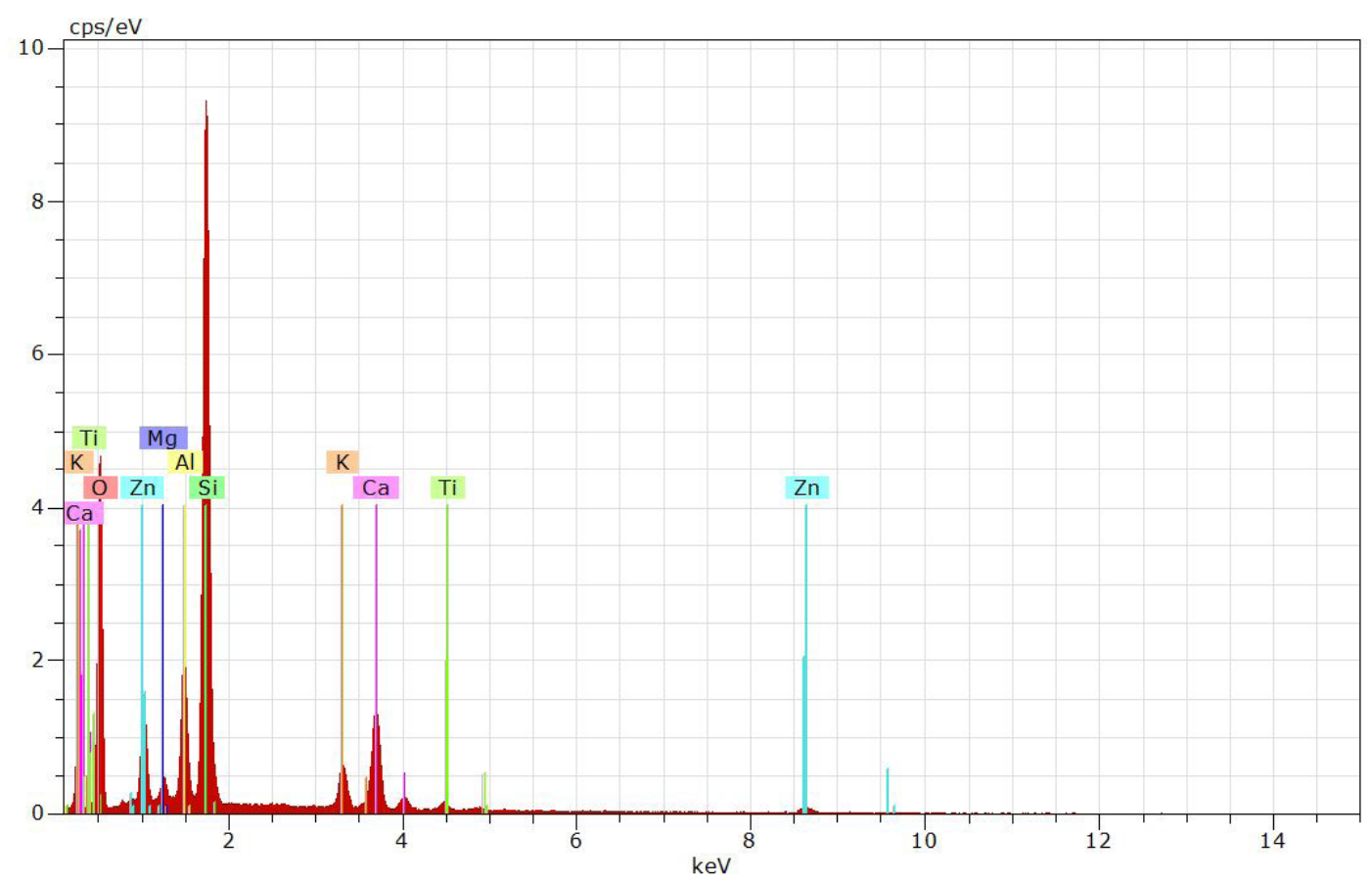

Figura 6. Análise elementar EDS do esmalte transparente VTG 066, obtida sobre a área da fig. 5 (I).

Tabela 3. Análise elementar (EDS) do esmalte transparente VTG 066, obtida sobre a área da fig. 5(I).

\begin{tabular}{cc}
\hline Elemento & \% mássica \\
\hline $\mathrm{O}$ & 42,03 \\
$\mathrm{Si}$ & 29,69 \\
$\mathrm{Zn}$ & 6,74 \\
$\mathrm{Ca}$ & 11,16 \\
$\mathrm{Al}$ & 5,20 \\
$\mathrm{~K}$ & 3,53 \\
$\mathrm{Mg}$ & 0,76 \\
$\mathrm{Ti}$ & 0,90 \\
\hline
\end{tabular}

Tabela 4. Análise elementar (EDS) do esmalte mate VMG 205, obtida sobre área da fig. 5(II).

\begin{tabular}{cc}
\hline Elemento & \% mássica \\
\hline $\mathrm{O}$ & 39,28 \\
$\mathrm{Si}$ & 26,17 \\
$\mathrm{Zn}$ & 5,02 \\
$\mathrm{Ca}$ & 16,22 \\
$\mathrm{Al}$ & 9,53 \\
$\mathrm{~K}$ & 2,44 \\
$\mathrm{Mg}$ & 1,28 \\
$\mathrm{Zr}$ & 0,05 \\
\hline
\end{tabular}


e alumina no esmalte VMG 205, sendo ligeiramente inferior os teores de zinco e de potássio, explicando estas diferenças, o carácter mate deste esmalte.

A difração de raios $\mathrm{X}$ dos esmaltes, figuras 8 e 9 , revela o carácter acentuadamente amorfo dos materiais, pela (quase) ausência de picos correspondentes à presença de compostos cristalinos. Desta forma garantem-se as características estéticas desejáveis: elevada transparência e brilho no caso do esmalte transparente e desenvolvimento de superfície mate-acetinada no esmalte mate.

A ausência de partículas cristalinas em volume considerável minimiza o seu arrancamento/destacamento durante a fase de polimento, principal causadora da formação de porosidade superficial.

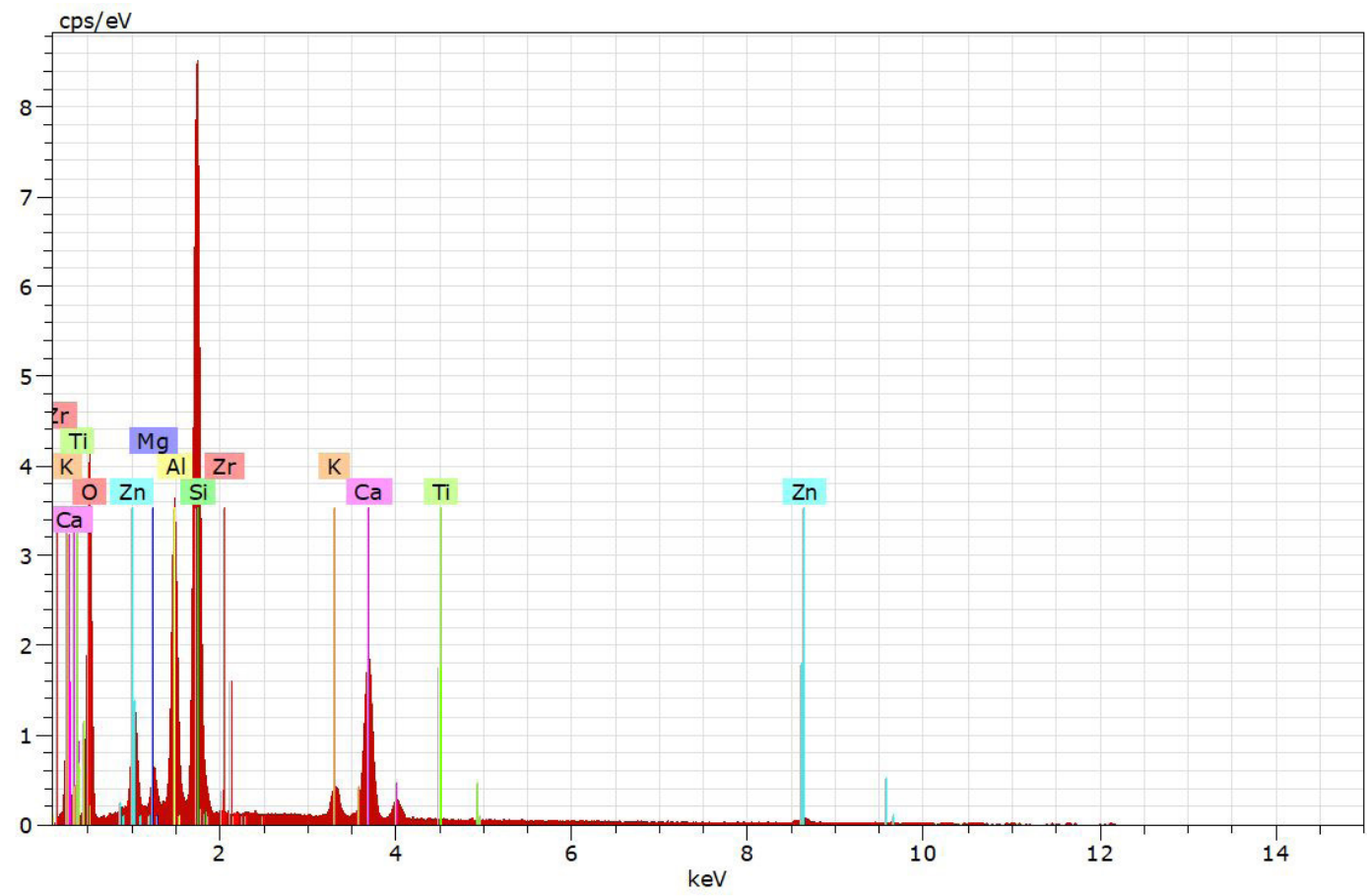

Figura 7. Análise elementar EDS do esmalte mate VMG 205, obtida sobre a área da fig. 5 (II).

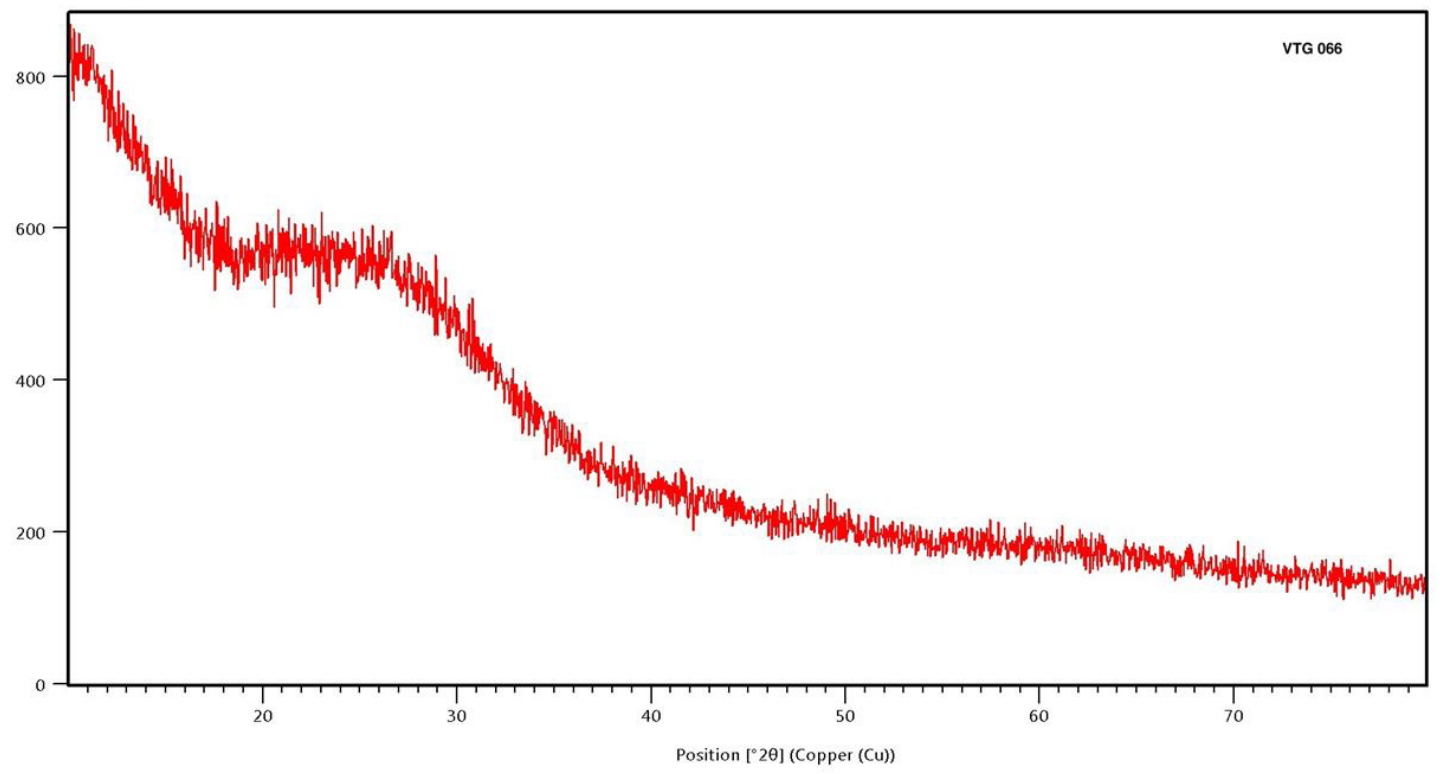

Figura 8. Difratograma de raios X do esmalte transparente VTG 066. 


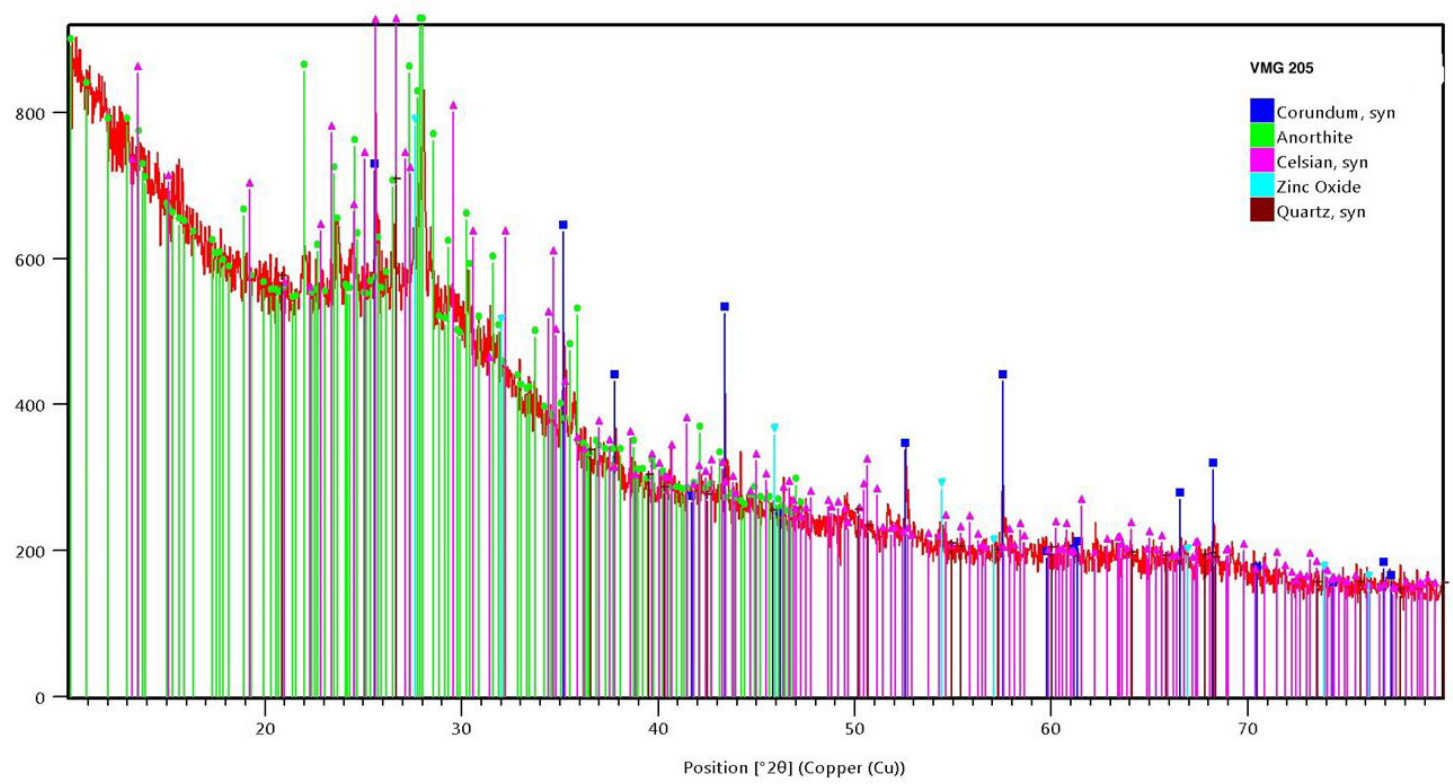

Figura 9. Difratogama de raios X do esmalte mate VMG 205.

Tabela 5. Durabilidade química, resistência à abrasão e dureza dos esmaltes, avaliados de acordo com as normas ISO.

\begin{tabular}{lccc}
\hline \multicolumn{1}{c}{ TESTES } & ISO 10545-14 & ISO 10545-13 & ISO 10545-7 \\
\hline Ataque às Manchas após polimento & 5 & & \\
Ataque químico (Ácidos-Bases) & & GLA-GHA & IV \\
Abrasão (PEI) antes polimento & & $6-7$ \\
Dureza (MOHS) após polimento & & \\
\hline
\end{tabular}

Sendo arriscada a correta identificação de fases cristalinas, ausentes no caso do esmalte transparente, ainda assim parece existir aluminato de cálcio (Anortita) e aluminosilicato de bário (Celsium) no esmalte mate.

A tabela 5 mostra resultados da resistência a manchas e aos agentes químicos, bem como da resistência à abrasão e de dureza de MOHS dos esmaltes aplicados.

A superfície das peças polidas não apresentou quaisquer indícios de manchamento por qualquer das soluções testadas, sendo ambos considerados de classe 5 . Este resultado é compatível com o desenvolvimento de superfícies polidas isentas de porosidade aberta.

A resistência ao ataque químico é igualmente excelente, tendo ambos os produtos obtido a classificação A perante todos os agentes agressivos utilizados. A classificação GLA-GHA é a que traduz maior resistência ao ataque químico e que pressupõe a não deteção de qualquer degradação na superfície das peças.

$\mathrm{O}$ teste de resistência à abrasão $(\mathrm{PEI})$ foi realizado em peças não polidas. Ambos os esmaltes pertencem à classe IV. A dureza de MOHS, estimada em peças polidas, foi igual a 6-7.

\section{Conclusões}

Os esmaltes desenvolvidos apresentam superfícies de elevada transparência e brilho no caso do esmalte transparente, e textura mate-acetinada no caso do esmalte mate. Ambos apresentam facilidade de polimento, do tipo "lapato", e ausência de porosidade superficial. Além disso, permitem decoração por InkJet, em sandwiche, com elevado desenvolvimento cromático.

Este tipo de esmaltes possibilita o armazenamento do produto final, tanto na forma brilhante como mate, sem exigência de polimento imediatamente após a produção. Esta operação pode ser realizada apenas quando necessário e de acordo com as solicitações comerciais.

Antes de polimento as peças apresentam valores de PEI IV, que permitem a sua utilização em áreas de tráfego considerável. A resistência às manchas é superior (classe 5), além de apresentarem resistência aos agentes químicos, sendo classificadas como produtos de classe GLA-GHA. Por estas razões conclui-se que as superfícies, brilhante e mate-acetinada, obtidas desta forma inovadora cumprem os requisitos exigidos pelas normas ISO em vigor.

\section{Referências}

[1] Juan B.Carda Castelló, Purificación Escribano Lôpez, Eloísa Cordoncillo, Esmaltes e Pigmentos Cerámicos, Faenza Editrice Iberica S.L. - Universitat Jaume I - Castellón, 2001.

[2] Oliveira H.J.C., dados técnicos, IFH - Estudio Cerâmico Lda, 2009-2017

[3] Oliveira H.J.C, Apontamentos Esmaltes Cerâmicos, Edições Almedina, Março 2017. 
[4] Sacmi Tecnologia Cerâmica Aplicada, volumen 1, Faenza Editrice Iberica, Castellon de la Plana, 2004.

[5] C. Agrafiotis, T. Tsoutos, Energy saving technologies in the European ceramic sector: a systematic review, Applied thermal engineering, 21, 1231-1249, 2001.
[6] Ed. Int. CERLabs, European Network of National Ceramic Laboratories, Ceramic Tiles the ISO International Standards for Ceramic Tiles, 1993.

[7] European committee for standardization, Ceramic tiles Definitions, classification, characteristics and marking, The European Standard, 2006. 